University of Nebraska - Lincoln

DigitalCommons@University of Nebraska - Lincoln

Faculty Papers and Publications in Animal

Science

Animal Science Department

October 2007

\title{
Estimates of genetic parameters for growth traits in Kermani sheep
}

\author{
M. R. Bahreini Behzadi \\ Department of Animal Sciences, Faculty of Agriculture, Yasouj University, Iran \\ F. E. Shahroudi \\ Department of Animal Sciences, Faculty of Agriculture, Ferdowsi University of Mashhad, Iran \\ L. Dale Van Vleck \\ University of Nebraska-Lincoln, dvan-vleck1@unl.edu
}

Follow this and additional works at: https://digitalcommons.unl.edu/animalscifacpub

Part of the Animal Sciences Commons

Behzadi, M. R. Bahreini; Shahroudi, F. E.; and Van Vleck, L. Dale, "Estimates of genetic parameters for growth traits in Kermani sheep" (2007). Faculty Papers and Publications in Animal Science. 173.

https://digitalcommons.unl.edu/animalscifacpub/173

This Article is brought to you for free and open access by the Animal Science Department at DigitalCommons@University of Nebraska - Lincoln. It has been accepted for inclusion in Faculty Papers and Publications in Animal Science by an authorized administrator of DigitalCommons@University of Nebraska - Lincoln. 
Published in Journal of Animal Breeding and Genetics, 124:5 (October 2007), pp. 296-301; doi 10.1111/j.1439-0388.2007.00672.x Copyright ( 2007 M. R. Bahreini Behzadi, F. E. Shahroudi, and L. D. Van Vleck; journal compilation @ 2007 Blackwell Verlag, Berlin. Used by permission. http://www.blackwellpublishing.com/journal.asp?ref=0931-2668\&site=1

\title{
Estimates of genetic parameters for growth traits in Kermani sheep
}

\author{
M. R. Bahreini Behzadi, Department of Animal Sciences, Faculty of Agriculture, Yasouj University, Iran \\ F. E. Shahroudi, Department of Animal Sciences, Faculty of Agriculture, Ferdowsi University of Mashhad, Iran \\ L. D. Van Vleck, Department of Animal Science, University of Nebraska-Lincoln, Lincoln, Nebraska, USA
}

Correspondence: Mohammad Reza Bahreini Behzadi, Department of Animal Sciences, Faculty of Agriculture, Yasouj University, Iran 75914-353. Tel: (98) 741 2224840; Fax: (98) 741 2224840; email: Bahreini@mail.yu.ac.ir ; bahreini2001@yahoo.com

\begin{abstract}
Birth weight (BW), weaning weight (WW), 6-month weight (W6), 9-month weight (W9) and yearling weight $(\mathrm{YW})$ of Kermani lambs were used to estimate genetic parameters. The data were collected from Shahrbabak Sheep Breeding Research Station in Iran during the period of 1993-1998. The fixed effects in the model were lambing year, sex, type of birth and age of dam. Number of days between birth date and the date of obtaining measurement of each record was used as a covariate. Estimates of (co)variance components and genetic parameters were obtained by restricted maximum likelihood, using single and two-trait animal models. Based on the most appropriate fitted model, direct and maternal heritabilities of BW, WW, W6, W9 and YW were estimated to be $0.10 \pm 0.06$ and $0.27 \pm 0.04$, $0.22 \pm 0.09$ and $0.19 \pm 0.05,0.09 \pm 0.06$ and $0.25 \pm 0.04,0.13 \pm 0.08$ and $0.18 \pm 0.05$, and $0.14 \pm 0.08$ and $0.14 \pm 0.06$ respectively. Direct and maternal genetic correlations between the lamb weights varied between 0.66 and 0.99 , and 0.11 and 0.99 . The results showed that the maternal influence on lamb weights decreased with age at measurement. Ignoring maternal effects in the model caused overestimation of direct heritability. Maternal effects are significant sources of variation for growth traits and ignoring maternal effects in the model would cause inaccurate genetic evaluation of lambs.
\end{abstract}

\section{Introduction}

The sheep population in Iran is composed mainly of fattailed carpet-wool native breeds. A high percentage of the sheep population is managed under a migratory system, utilizing the ranges as the major source of feed. The Kermani is a fat-tail breed in eastern Iran which has a dry and hot climate. Coat color is white with pigmented head and legs. The wool is coarse.

To determine optimal breeding strategies to increase the efficiency of sheep production, knowledge of genetic pa- rameters for weight traits at various ages and also the genetic relationships between the traits is needed. Various environmental effects on lamb growth have previously been studied in several investigations on other breeds (Boujenane et al. 1991; Jorgensen et al. 1993; Yazdi et al. 1997). By far, the most important environmental factors are year, sex, type of birth, age of dam, and age of lambs at weighing. Many random factors affect the growth of lambs. These factors include direct genetic effects, maternal genetic effects, and environmental factors, which affect both the lamb and its dam. Studies of various sheep breeds have 
shown that both direct and maternal genetic influences are of importance for lamb growth (Maria et al. 1993; Tosh \& Kemp 1994; Nasholm \& Danell 1996; Yazdi et al. 1997; Jara et al. 1998). Hence, to achieve optimum genetic progress in a selection programme both the direct and maternal components should be taken into account (Meyer 1992; Maria et al. 1993).

There are no reports on genetic parameters for growth traits of Kermani sheep. The objective of this study was to estimate the variances and covariances for direct and maternal genetic effects on lamb weights at different ages. In addition, the correlations between the traits were estimated.

\section{Material and methods}

The data used in the present study, were collected at the Shahrbabak Sheep Breeding Station in Kerman province of Iran from 1993 to 1998. Five traits were considered: birth weight (BW), weaning weight (WW), 6-month weight (W6), 9-month weight (W9), and yearling weight (YW). The unadjusted characteristics of the data are shown in Table 1.

In general, animals were managed following conventional industrial practices. Natural pasture is the main source of feed. The quantity and quality of the pasture vary considerably during the year. With the dry season, the quantity and quality of the pasture decreases and supplemental feeding has to be provided especially at the time of flushing and winter. The mating period began between late summer (August) and early autumn (September). Lambings were in February and March. The lambs were weaned at about 3 months of age.

The SAS statistical package (SAS 1985) and the method of unequal subclass analysis of variance was used to test the significance of the fixed effects of year of birth (5 levels), sex (male and female), type of birth (single and twin), and age of dam $(2,3,4$, and 5 years of age or older).

Table 1 Characteristics of the data structure

\begin{tabular}{llllll}
\hline Character & BW & WW & W6 & W9 & YW \\
\hline Mean $(\mathrm{kg})$ & 3.32 & 21.98 & 24.98 & 26.33 & 24.86 \\
Standard deviation $(\mathrm{kg})$ & 0.47 & 4.40 & 4.85 & 5.13 & 5.91 \\
Coefficient of variation $(\%)$ & 14.24 & 20.04 & 19.43 & 19.49 & 23.78 \\
Number of records & 1182 & 1099 & 1054 & 765 & 590 \\
Number of sires & 29 & 29 & 29 & 29 & 29 \\
Number of dams & 479 & 473 & 460 & 389 & 345 \\
\hline
\end{tabular}

BW, birth weight; WW, weaning weight; W6, 6-month weight; W9, 9month weight; $Y W$, yearling weight.
Variance and covariance components and genetic parameters were estimated using the MTDFREML program (Boldman et al. 1995) by fitting six single-trait animal models. The analysis of variance showed that fixed effects of year of birth, sex and age of dam were significant for all five traits. Consequently, those effects were included in all six models for those traits. The effect of birth type was only significant for weaning weight, and was included in models for weaning weight. Number of days between birth date and the date of measurement for each record was used as a covariate. Univariate analyses for each trait and data set were carried out considering six different models to assess the importance of maternal effects. The random models used are summarized in Table 2.

Total heritability $\left(h_{t}^{2}\right)$, is as defined by Willham (1972):

$$
h_{t}^{2}=\left(\sigma_{a}^{2}+0.5 \sigma_{m}^{2}+1.5 \sigma_{a m}\right) / \sigma_{p}^{2}
$$

Estimation of (co)variance components was carried out using the MTDFREML program. A simplex algorithm is used to search for variance components to minimize the function, $-2 \log$ likelihood (L). Convergence was assumed when the variance of the function values $(-2 \log L)$ of the simplex was less than $10^{-8}$. For all models, a restart was performed after a first convergence to verify that convergence was not at a local minimum. A log likelihood ratio test was used to choose the most suitable random effects model for each trait. The reduction in $-2 \log \mathrm{L}$ when a random effect was added to the model was calculated. If this reduction was greater than the value of the chi-square distribution with one degree of freedom $(p<0.05)$, the additional random effect fitted was considered significant. When log likelihoods did not differ significantly $(\mathrm{p}>0.05)$, the model that had the fewer number of parameters was selected as the most appropriate.

Two-trait analyses were carried out between the traits to estimate the correlations. The same model (Model 3, cf. Table 3) was used for all traits.

Table 2 Description of animal models fitted

\begin{tabular}{cl}
\hline Model & (Co)Variance components estimated ${ }^{1}$ \\
\hline 1 & $\sigma_{a}^{2}, \sigma_{e}^{2}$ \\
2 & $\sigma_{a}^{2}, \sigma_{c}^{2}, \sigma_{e}^{2}$ \\
3 & $\sigma_{a}^{2}, \sigma_{m}^{2}, \sigma_{e}^{2}$ \\
4 & $\sigma_{a}^{2}, \sigma_{m}^{2}, \sigma_{a m}, \sigma_{e}^{2}$ \\
5 & $\sigma_{a}^{2}, \sigma_{m}^{2}, \sigma_{c}^{2}, \sigma_{e}^{2}$ \\
6 & $\sigma_{a}^{2}, \sigma_{m}^{2}, \sigma_{a m}, \sigma_{c}^{2}, \sigma_{e}^{2}$ \\
\hline
\end{tabular}

$\overline{\sigma_{a}^{2}}$, direct additive genetic variance; $\sigma_{m}^{2}$, maternal additive genetic variance; $\sigma_{a m}$, direct-maternal genetic covariance; $\sigma_{c}^{2}$, common environment variance; $\sigma_{e}^{2}$, residual variance. 
Table 3 Least square means $( \pm S E)^{1}$ for all traits ${ }^{2}$

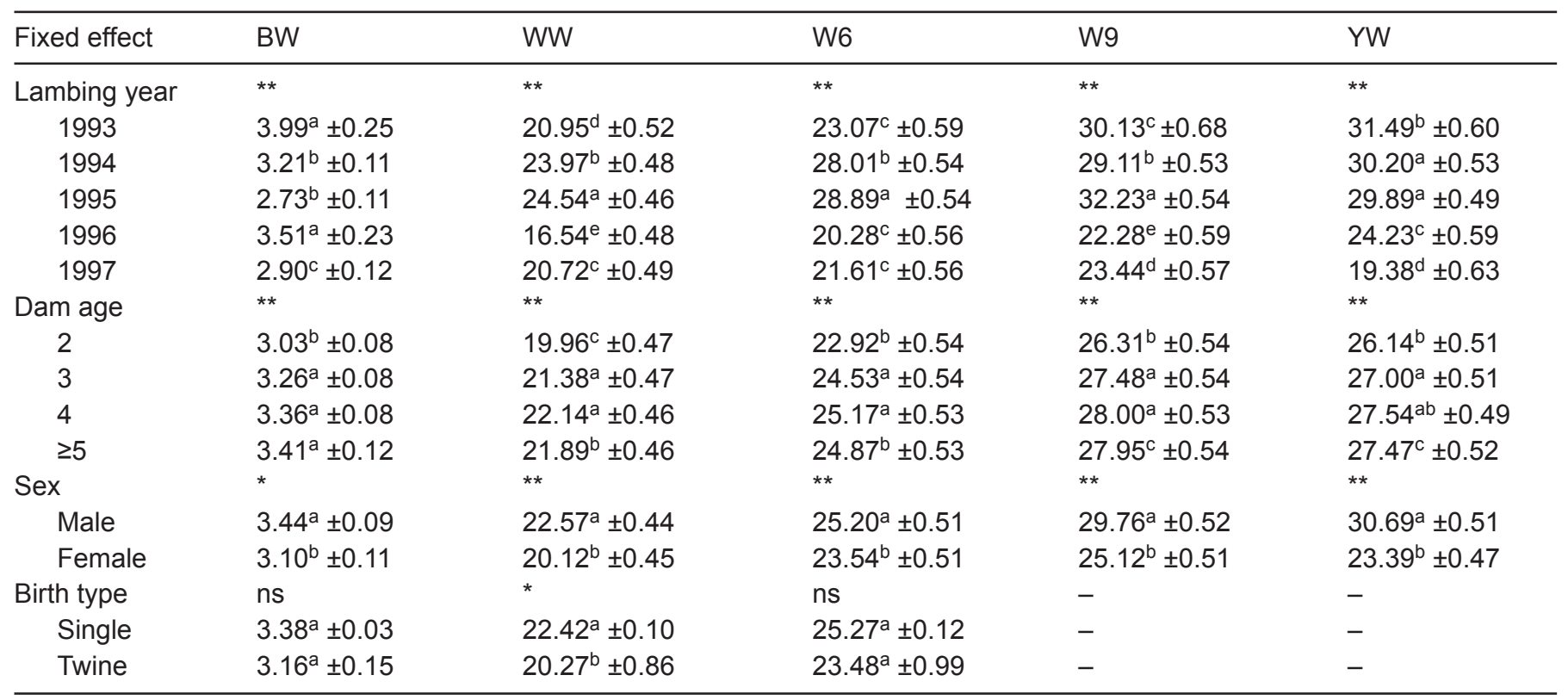

${ }^{1}$ Means within a column that do not have a common superscript are significantly different $(p<0.05)$.

${ }^{2}$ BW, birth weight; WW, weaning weight; W6, six month weight; W9, nine month weight; YW, yearling weight.

\section{Result and discussion}

The mean values for the different traits (Table 1) are smaller than those of the studies of other breeds (Yazdi et al. 1997), probably due to the more extensive conditions under which the herd was maintained. Kerman in Iran is a province with a relatively low rainfall, which has a great influence on the amount of available forage. The coefficient of variation for birth weight is much less than that for the other traits, which is an indication of the smaller effect of environment on birth weight than on the other traits. About $50 \%$ of the lambs were lost from birth until 12 months of age due to mortality and insufficient or low quality of pasture which resulted in some of the lambs being sold.

Least square means $( \pm \mathrm{SE})$ for the various traits are shown for each subclass in Table 3. All the fixed effects (year of birth, age of dam, and sex) except birth type were significant for lamb weight at all ages. Type of birth had a significant effect only on weaning weight. Male lambs were heavier than females and the difference between the two sexes increased with age of lamb, probably because of increasing differences in the endocrine system between males and females. Lambs born to parity four or five ewes were heavier than lambs of younger ewes. The differences in weight between lambs born to first parity and to later parity ewes were significant. These environmental factors were also important in other studies of body development of lambs (Boujenane et al. 1991; Jorgensen et al. 1993; Yazdi et al. 1997).

Estimates of genetic parameters in single-trait analyses are presented in Table 4. Model 1, which ignored maternal effects, resulted in larger estimates for $\sigma_{a}^{2}$ and $h_{a}^{2}$ compared with other models. With Models 2 and 3, the addition of the maternal environmental effect and maternal genetic effect increased the $\log$ likelihood values significantly $(\mathrm{p}<0.05)$ and reduced the estimates of both $\sigma_{a}^{2}$ and $h_{a}^{2}$ compared with Model 1. Meyer (1992) showed that models not accounting for maternal genetic effects could result in substantially higher estimates of additive direct genetic variance and, therefore, higher estimates of $h_{a}^{2}$. If maternal effects are present but not considered, the estimate of additive genetic variance will include at least part of the maternal variance. Therefore, estimates of direct heritability will decrease when maternal effects are included. Model 3, which included an additive maternal effect, yielded smaller estimates of $\sigma_{a}^{2}$ and $h_{a}^{2}$ than did Models 1 and 2. The additive maternal genetic effect was determined to be more important than the permanent maternal environmental influence of the dam for these traits of Kermani sheep. Models 3, 4, 5 and 6 had the highest log likelihood values and differences between these models were not significant $(p>0.05)$. On the basis of log likelihood values, Models 3, 4,5 , and 6 were significantly better $(\mathrm{p}<0.05)$ than Models 1 and 2 . On the basis of the log likelihood ratio test results 
Table 4 Estimates of genetic parameters ${ }^{1}$ for body weights ${ }^{2}$ from single-trait analyses

\begin{tabular}{|c|c|c|c|c|c|c|c|c|c|}
\hline Trait & Model & $h_{a^{+}}^{2} \pm$ S.E. & $h_{m}^{2} \pm$ S.E. & $r_{\mathrm{am}}$ & $c^{2}$ & $e^{2}$ & $h_{t}^{2}$ & $\sigma_{p}^{2}$ & $-2 \log \mathrm{L}$ \\
\hline \multirow[t]{3}{*}{ BW } & 1 & $0.62 \pm 0.07$ & - & - & - & 0.38 & 0.62 & 0.21 & -787.61 \\
\hline & 3 & $0.10 \pm 0.06$ & $0.27 \pm 0.04$ & - & - & 0.64 & 0.24 & 0.19 & -817.57 \\
\hline & 4 & $0.10 \pm 0.06$ & $0.33 \pm 0.08$ & -0.35 & - & 0.64 & 0.17 & 0.19 & -818.28 \\
\hline \multirow[t]{2}{*}{ WW } & 1 & $0.59 \pm 0.08$ & - & - & - & 0.41 & 0.59 & 10.45 & 3539.49 \\
\hline & 3 & $0.22 \pm 0.09$ & $0.19 \pm 0.05$ & - & - & 0.59 & 0.32 & 9.68 & 3527.79 \\
\hline \multirow{2}{*}{ W6 } & 3 & $0.09 \pm 0.06$ & $0.25 \pm 0.04$ & - & - & 0.65 & 0.22 & 11.72 & 3582.04 \\
\hline & 4 & $0.10 \pm 0.06$ & $0.17 \pm 0.07$ & 0.63 & - & 0.65 & 0.31 & 11.80 & 3580.85 \\
\hline \multirow[t]{3}{*}{ W9 } & 1 & $0.41 \pm 0.09$ & - & - & - & 0.59 & 0.41 & 9.17 & 2416.65 \\
\hline & 3 & $0.13 \pm 0.08$ & $0.18 \pm 0.05$ & - & - & 0.69 & 0.22 & 8.75 & 2406.64 \\
\hline & 4 & $0.12 \pm 0.08$ & $0.10 \pm 0.08$ & 0.74 & - & 0.69 & 0.29 & 8.78 & 2405.49 \\
\hline
\end{tabular}

${ }^{1} h_{a}^{2}$, direct heritability; $h_{m}^{2}$, maternal heritability; $r_{a m}$, direct-maternal genetic correlation; $c^{2}$, maternal permanent environment variance as a proportion of phenotypic variance; $\mathrm{e}^{2}$, residual variance as a proportion of phenotypic variance; $h_{t}^{2}$, total heritability; $\sigma_{p}^{2}$, phenotypic variance.

${ }_{2}^{p} \mathrm{BW}$, birth weight; WW, weaning weight; W6, six month weight; W9, nine month weight; YW, yearling weight.

and number of parameters used, Model 3 was determined to be the most appropriate model for all traits.

Estimates presented in the literature have been summarized by Snyman et al. (1995) and by Nasholm \& Danell (1996). Furthermore, Yazdi et al. (1997) and Ekiz et al. (2004) presented estimates of genetic parameters for lamb weights. Heritability estimates vary substantially in these studies. The estimates of $h_{a}^{2}$ and $h_{m}^{2}$ reported by several authors were $0.04-0.39$ and $0.09-0.31$ for birth weight and $0.06-0.39$ and $0.01-0.38$ for weaning weight, depending on the model used and the breed of lamb.

Direct heritabilities for body weights showed a tendency to increase with age measured, because estimates of direct additive genetic variance component increased faster than the environmental variance components. Tendency for estimates of direct heritability to increase with age measured has also been reported in several studies (Mavrogenis et al. 1980; Yazdi et al. 1997).

For all traits, estimates of maternal heritability, were as large as or larger than the estimates of direct heritability. This suggests that maternal effects need to be considered in selecting for growth in Kermani sheep. Estimates of maternal heritability tended to decline from birth to yearling weight. Maternal genetic effects expressed during gestation and lactation had been expected to have a diminishing influence on weight as lambs became older. Maternal heritability decreased with age, which confirms the proposal by Robison (1981) that maternal effects in mammals are substantial in young animals but diminish with age. Maternal heritability estimates of birth and weaning weights in this study were higher than values reported by Maria et al. (1993), Snyman et al. (1995), Yazdi et al. (1997), Saatci et al. (1999), Ligda et al. (2000), Neser et al. (2001), and Ekiz et al. (2004) for several sheep breeds. The high estimates of maternal heritability for 9-month and yearling weights were unexpected because at these ages individuals do not depend on their mother and their weights should reflect only the direct effect of the genes on growth except for carry over maternal effects from before weaning. Similar results, however, were reported by Yazdi et al. (1997) for Baluchi sheep. For animals raised on pasture without any supplementary feeding, the length of time from birth to yearling is probably not enough that compensatory gain could buffer completely the maternal effect existing at birth. Robison (1981) suggested that even if maternal effects tend to diminish with age, some adult traits will nevertheless contain this source of variation.

In general, the trend of increasing direct heritabilities and decreasing maternal heritabilities with age in Kermani sheep are similar to the average trends reported for other breeds. The direct and maternal heritability estimates for lamb body weights found in the present study are within the range of those presented in literature. The relatively low heritability estimates for growth traits in 
this study can be explained by the low nutritional level and poor quality of the pasture at the sheep breeding station, creating large environmental variations. The large approximate standard errors associated with the heritability estimates are possibly the results of the small sample size used in this study.

The correlations between the direct and maternal genetic effects $\left(r_{\text {am }}\right)$ were positive for all traits, except for birth and yearling weights. These genetic correlations ranged from 0.35 to 0.74 for the various age stages. Negative estimates of $r_{\text {am }}$ were reported by Maria et al. (1993), Tosh and Kemp (1994), Jara et al. (1998), Ligda et al. (2000), and Ekiz et al. (2004) for several sheep breeds. However, Nasholm and Danell (1996) and Yazdi et al. (1997) reported a positive correlation for Swedish Finewool and Baluchi lambs respectively. Maria et al. (1993) found extreme direct-maternal genetic correlations $(0.97 \leq)$ for lamb weights in Romanovs. Result for birth weight suggested that the negative correlation could be due to a negative direct influence of the dams on the maternal ability of their female offspring through overfeeding. Negative correlation $\left(r_{\mathrm{am}}\right)$ for yearling weight may be the result of an adaptation of the animals to the dry and hot environment where food resources are scarce. The positive direct-maternal genetic correlations suggest that selection for increased body weight of the lamb will also improve the maternal ability of the ewe. In spite of this facts, we have to be cautious with the estimates obtained in this study, and probably it would be necessary to check them again with larger data sets. There was no significant reduction in the log likelihood value when adding the direct-maternal additive covariance to the appropriate simpler model.

The residual variance estimates were large. The ratios of the residual to the phenotypic variance $\left(e^{2}\right)$ ranged from 59 to $73 \%$.

Estimates of correlations between various body weights in two-trait analyses are presented in Table 5. Phenotypic correlations between various stages of body development were positive and increased with older pairs of ages. The corresponding direct and maternal genetic correlations were all positive as well as the environmental correlations, with a tendency for higher estimates between pairs of older ages. Phenotypic correlations were generally less than corresponding genetic correlations. In previous studies, direct genetic correlations ranged from 0.12 to 0.96 (Maria et al. 1993; Yazdi et al. 1997; Jara et al. 1998; McManus \& Miranda 1998).

The large direct genetic correlation between birth and weaning weights indicates that selection on weaning weight may lead to an increase in birth weight. The direct genetic correlations between weight at weaning and later weights
Table 5 Estimates of correlations ${ }^{1}$ between various weights ${ }^{2}$ from two-trait analyses

\begin{tabular}{llllll}
\hline Trait 1 & Trait 2 & $\mathrm{r}_{\mathrm{a} 1 \mathrm{a} 2}$ & $\mathrm{r}_{\mathrm{m} 1 \mathrm{~m} 2}$ & $\mathrm{r}_{\mathrm{e} 1 \mathrm{e} 2}$ & $\mathrm{r}_{\mathrm{P} 1 \mathrm{P} 2}$ \\
\hline BW & WW & 0.82 & 0.92 & 0.29 & 0.48 \\
BW & 6W & 0.90 & 0.78 & 0.23 & 0.45 \\
BW & $9 \mathrm{~W}$ & 0.84 & 0.85 & 0.14 & 0.38 \\
BW & YW & 0.66 & 0.85 & 0.09 & 0.36 \\
WW & 6W & 0.95 & 0.11 & 0.48 & 0.78 \\
WW & $9 W$ & 0.99 & 0.99 & 0.40 & 0.75 \\
WW & YW & 0.92 & 0.80 & 0.51 & 0.67 \\
6W & $9 W$ & 0.96 & 0.89 & 0.74 & 0.81 \\
6W & YW & 0.94 & 0.91 & 0.61 & 0.73 \\
9W & YW & 0.99 & 0.28 & 0.73 & 0.83 \\
\hline
\end{tabular}

${ }^{1} \mathrm{r}_{\mathrm{a} 1 \mathrm{a} 2}$, genetic correlation between direct effects of traits 1 and 2; $r_{\mathrm{m} 1 \mathrm{~m} 2}$, genetic correlation between maternal effects of traits 1 and 2 ; $\mathrm{r}_{\mathrm{e} 1 \mathrm{e} 2}$, environmental correlation between traits 1 and $2 ; \mathrm{r}_{\mathrm{P} 1 \mathrm{P} 2}$, phenotipic correlation between traits 1 and 2 .

${ }^{2}$ BW, birth weight; WW, weaning weight; W6, six month weight; W9, nine month weight; YW, yearling weight.

were high, indicating that selection for increased $\mathrm{WW}$ in Kermani sheep will also result in genetic change for W6, W9, and YW. Therefore, it is reasonable to suggest that the traits to be included in the sheep recording scheme could be confined to the traits expressed early in life of the lambs, such as their birth weight and weaning weight in which both the direct and maternal effects are involved. The estimate of the additive direct correlation between birth and yearling weights was less than that between weaning and yearling weights, indicating that selection for yearling weight would not quickly result in increased birth weight.

The positive maternal genetic correlations of birth weight with later weights indicate that maternal influences on the later weights are partly originating from the prenatal period. The results with higher maternal heritability for birth weight than for all later weights also support this conclusion. Genetic correlations among growth traits of Kermani lambs were, all, positive, indicating that selection for any of the traits should result in positive genetic change in the other traits.

\section{Conclusions}

The estimates of genetic parameters reported for the Kermani lambs here are in general agreement with those reported in the literature. This study showed that the addition of maternal effects to the model resulted in a decrease in the estimates of direct heritability for all weight traits of Kermani sheep. Maternal effects remained important at 
1 year of age in this breed of sheep. In conclusion, maternal effects on weights in different ages of Kermani sheep were significant and should be taken into consideration in any selection program on this breed. The genetic parameters estimated for growth traits indicate that there is genetic variation among the animals that can be utilized for genetic change in these traits by selection in Kermani sheep raised under their specific harsh environmental conditions.

\section{References}

Boldman K.G., Kriese L.A., Van Vleck L.D., Van Tassell C.P., Kachman S.D. (1995) A Manual for Use of MTDFREML. A Set of Programs to Obtain Estimates of Variances and Covariances [Draft]. U. S. Department of Agriculture, Agricultural Research Service, Clay Center, NE.

Boujenane I., Bradford G.E., Berger Y.M., Chikhi A. (1991) Genetic and environmental effects on growth to 1 year and viability of lambs from a crossbreeding study of D'man and Sardi breeds. $J$. Anim. Sci., 69, 3989-3998.

Ekiz B., Ozcan M., Yilmaz A. (2004) Estimates of genetic parameters for direct and maternal effects with six different models on birth and weaning weights of Turkish Merino lambs. Turk. J. Vet. Anim. Sci., 28, 383-389.

Jara A., Montaldo H., Barria N. (1998) Direct and maternal genetic effects for birth, weaning and 14 month weights of Corriedale breed in Magallanes. In: Proceedings of the 6th World Congress of Genetics Applied to Livestock Production, Armidale, Australia, pp. 181-184, CD-ROM

Jorgensen J.N., Henning-Petersen P., Ranvig H. (1993) Environmental factors influencing lamb growth in six Danish sheep breeds. Acta. Agric. Scand., Sect. A, Animal Sci., 43, 16-22.

Ligda C.H., Gavriilidis G., Papodopoulos T.H., Georgoudis A. (2000) Investigation of direct and maternal genetic effects on birth and weaning weight of Chios lambs. Livest. Prod. Sci., 67, 75-80.

Maria G.A., Boldman K.G., Van Vleck L.D. (1993) Estimates of variances due to direct and maternal effects for growth traits of Romanov sheep. J. Anim. Sci., 71, 845-849.
Mavrogenis A.P., Louca A., Robison O.W. (1980) Estimates of genetic parameters for pre-weaning and post-weaning growth traits of Chios lambs. Anim. Prod., 30, 271-276.

McManus C.M., Miranda R.M. (1998) Genetic analysis of production characteristics of Grade Bergamasca sheep reared in the Brasilia region. In: Proceedings of the 6th World Congress of Genetics Applied to Livestock Production, Armidale, Australia, pp. 226-229, CD-ROM.

Meyer K. (1992) Variance components due to direct and maternal effects for growth traits of Australian beef cattle. Livest. Prod. Sci., 31, 179-204.

Nasholm A., Danell O. (1996) Genetic relationships of lamb weight maternal ability and mature ewe weight in Swedish Finewool sheep. J. Anim. Sci., 74, 329-339.

Neser F.W.C., Erasmus G.J., Van Wyk J.B. (2001) Genetic parameter estimates for pre-weaning weight traits in Dorper sheep. Small Rumin. Res., 40, 197-202.

Robison O.W. (1981) The influence of maternal effects on the efficiency of selection; A review. Livest. Prod. Sci., 8, 121-137.

Saatci M., Dewi I.A., Ulutas Z. (1999) Variance components due to direct and maternal effects and estimation of breeding values for 12-week weight of Welsh Mountain lambs. J. Anim. Sci., 69, $345-352$

SAS (1985) User's Guide, version 5. SAS Institute, Cary, NC.

Snyman M.A., Erasmus G.J., Van Wyk J.B., Olivier J.J. (1995) Direct and maternal (co)variance components and heritability estimates for body weight at different ages and fleece traits in Afrino sheep. Livest. Prod. Sci., 44, 229-235.

Tosh J.J., Kemp R.A. (1994) Estimation of variance components for lamb weights in three sheep populations. J. Anim. Sci., 72, 1184-1190.

Willham R.L. (1972) The role of maternal effects in animal breeding: III. Biometrical aspects of maternal effects in animals. J. Anim. Sci., 35, 1288-1293.

Yazdi M.H., Engström G., Nasholm A., Johansson K., Jorjani H., Liljedahl L.E. (1997) Genetic parameters for lamb weight at different ages and wool production in Baluchi sheep. Anim. Sci., 65, 224-255. 